Diabetologe 2011 · 7:246

DOI 10.1007/s11428-011-0705-0

Online publiziert: 20. Mai 2011

(c) Springer-Verlag 2011

\author{
C.A. Schneider ${ }^{1,2}$ \\ ${ }^{1}$ Innere Medizin - Kardiologie, PAN-Klink Köln \\ ${ }^{2}$ Klinik III für Innere Medizin, Herzzentrum, Universität zu Köln
}

\title{
Diabetes und Herz
}

zu klärenden Fragen stehen z. B.: Macht es beim symptomfreien Diabetiker Sinn, auf Herzinsuffizienz zu screenen? Dies wäre z. B. mit „Point-of-care“-Tests für „B-type natriuretic peptide“ (BNP) ohne größeren Aufwand möglich, der prognostische Nutzen eines solchen Vorgehens ist bislang jedoch nicht dokumentiert. Was ist die optimale Therapie der diastolischen Herzinsuffizienz beim Diabetiker? Nach den enttäuschenden Studien der letzten Jahre erwartet der Autor von der Therapie mit Aldosteronantagonisten möglicherweise hier einen Durchbruch. Gibt es eine Bedeutung der telemedizinischen Betreuung bei Patienten mit Diabetes und Herzinsuffizienz? Die bislang verfügbaren randomisierten Studien zeigen gemischte Ergebnisse; Studien mit Diabetikern und Herzinsuffizienz fehlen völlig. blutzuckersenkende Therapie gemeint.

Auf dem mühsamen Weg des Erkenntnisgewinns sollen die 3 Beiträge dieses Hefts helfen. Pfister u. Schneider beleuchten zunächst den Zusammenhang von Diabetes mellitus und Herzinsuffizienz und zeigen, dass die Prognose ungünstig und die optimale blutzuckersenkende Therapie unbekannt ist. Pfützner u. Forst setzen sich mit der Frage auseinander, ob eine Insulintherapie gut für das Herz ist und demonstrieren, dass trotz einer jahrzehntelangen Therapie mit diesem Medikament immer noch keine abschließende Einschätzung möglich ist. Im dritten Beitrag fasst Schneider Daten zur Hypoglykämie zusammen und kommt zu dem Schluss, dass eine optimale, blutzuckersenkende Therapie möglichst hypoglykämiefrei sein muss, um das Herz zu schützen.

Die Klammer um diesen Beitrag bildet die erstaunliche Erkenntnis, dass eine Vielzahl drängender Fragen bislang in randomisierten Studien unbeantwortet ist. Auf der persönlichen Hitliste des Autors der

\section{() Eine Vielzahl drängender Fragen ist bislang in randomisierten Studien unbeantwortet geblieben}

Welche blutzuckersenkenden Medikamente sollten bei Herzinsuffizienz bevorzugt werden? Aus Sicht des Autors bietet sich hier in erster Linie Metformin an, auch wenn in der Fachinformation diesbezüglich ein Warnhinweis besteht. Als weitere Partner könnten z. B. „Glucagon-like peptide-1“- (GLP1-)Analoga oder Dipeptidylpeptidase- (DPP-)IV-Inhibitoren fungieren. Sulfonylharnstoffe sollten nach Ansicht des Autors nicht eingesetzt werden.

Welche Insulinpräparationen oder Insulinprotokolle verbessern die Prognose? Wenn ja, bei welchen Patienten? Sicher sollte hier einer möglichst hypoglykämiearmen Therapie der Vorzug gegeben werden. Ist ein $\mathrm{HbA}_{1 \mathrm{c}}$-Zielwert von $7,5 \%$ bei Patienten mit koronarer Herzerkrankung und/oder Herzinsuffizienz ausreichend? Retrospektive Subgruppenanalysen und epidemiologische Untersuchungen weisen in diese Richtung.

Was ist die optimale, hypoglykämiefreie, blutzuckersenkende Therapie für Patienten mit koronarer Herzerkrankung? Gibt es Biomarker des Hypoglykämierisikos oder der Hypoglykämiehäufigkeit (endogene Hypoglykämiemarker)? Ist die Hypoglykämie per se Ursache der ungünstigen Prognose oder nur ein Begleitphänomen anderer noch unbekannter Veränderungen? Auf all diese Fragen werden in den nächsten Jahren Antworten aus randomisierten, prospektiven Studien erwartet.

Wie gesagt, es bleibt beim kleinschrittigen, selbstkritischen Erkenntnisgewinn...

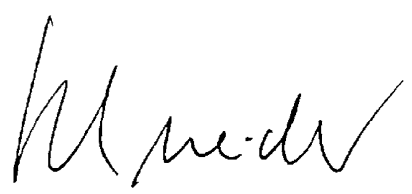

C.A. Schneider

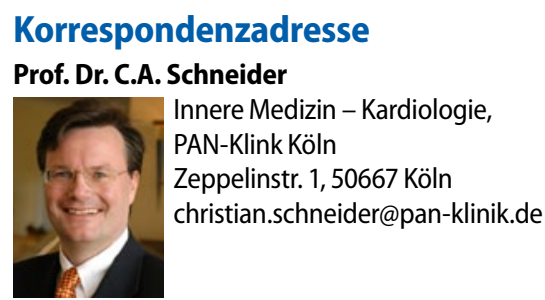

\section{Literatur}

1. Ray Kausik K, Seshasai SR, Wijesuriya S et al (2009) Effect of intensive control of glucose on cardiovascular outcomes and death in patients with diabetes mellitus: a meta-analysis of randomised controlled trials. Lancet 373:1765-1772

2. Trikalinos T, Alsheikh-Ali AA, Tatsioni A et al. (2009) Percutaneous coronary interventions for non-acute coronary artery disease: a quantitative 20-year synopsis and a network meta-analysis. Lancet 373:911-918 